Эмиров С.Н., Бейбалаев В.Д., Аливердиев А.А. Расчет теплопроводности гранулитов в зависимости от давления и температуры

\title{
УДК 536.2
}

DOI: $10.21779 / 2542-0321-2020-35-3-31-35$

\section{С.Н. Эмиров ${ }^{1}$ В.Д. Бейбалаев ${ }^{1,2,3}$, А.А. Аливердиев ${ }^{1,2}$}

Расчет теплопроводности гранулитов в зависимости от давления и температуры

${ }^{1}$ Институт проблем геотермии и возобновляемой энергетики филиал ОИВТ РАН; Россия, Республика Дагестан, 367030, г. Махачкала, пр. Шамиля, 43a; wemirov@mail.ru;

2 Дагестанский государственный университет; Россия, Республика Дагестан, 367000, г. Махачкала, ул. М. Гаджиева, 43a; kaspij_03@mail.ru;

3 Дагестанский государственный университет народного хозяйства; Россия, Республика Дагестан, 367008, г. Махачкала, ул. Джамалутдина Атаева, 5.

В статье представлено выведенное на основе экспериментальных данных образцов саксонских гранулитов (Германия) эмпирическое уравнение для расчета температурно-барических зависимостей теплопроводности в широких диапазонах температур (273-473 К) и давлений (от атмосферного до 400 МПа). Экспериментальные измерения теплопроводности проводились абсолютным стационарным методом. Средой, передающей давление, служил газ аргон. Показано, что полученное уравнение хорошо описывает экспериментальные данные и вариацией входящих в уравнение параметров можно описать температурно-барические зависимости для широкого ряда горных пород. В качестве сравнения проведён расчет температурно-барической зависимости для дагестанских песчаников. Полученные аналитические выражения помогут моделированию процессов теплопереноса и прогнозированию глубинных температур, в т. ч. в призабойной зоне.

Ключевые слова: теплопроводность, давление, температура, гранулиты.

\section{Введение}

Количественное описание теплообмена в композитных структурированных и пористых структурах искусственного естественного и естественного происхождения в широком диапазоне температур и давлений не теряет актуальности в связи с широким спектром прикладных задач прикладной инженерии и наук о Земле, где описание температурного поля недр имеет первостепенное значение.

Хорошо известно, что в таких структурах всесторонние напряжения достаточно сложного характера, которые, с одной стороны, приводят к изменению объёма и упругих параметров решётки, с другой - к развитию поперечных и продольных деформаций. Ряд авторов также указывает на возможность обратимого барического фазового перехода второго рода.

Влияние давления на теплопроводность горных пород исследовалось в [1-7]. В работах [9-11] также изучались барические зависимости тесно связанных с тепловыми характеристиками механических свойств, в частности, скорости упругих волн. Исследования показали, что быстрый рост величины теплопроводности и скорости звука происходит до $P \approx 100$ МПа. В первую очередь это вызвано тем, что именно в этом барическом диапазоне поры захлопываются, а межгранульные контакты уплотняются. Следует отметить, что, как правило, в барических зависимостях горных пород [12] после давления 100 МПа делается линейная аппроксимация и влияние давления на характер температурной зависимости не рассматривается.

В работе приводится описание температурно-барической зависимости теплопроводности образцов гранулитов. 


\section{Анализ экспериментальных данных}

Для проведения сравнительного экспериментального исследования температурной и барической зависимости теплопроводности были взяты природные образцы саксонских гранулитов (Германия) плотностью $\rho=2.06 \cdot 10^{3} \mathrm{\kappa} / \mathrm{M}^{3}$, пористостью $k=1 \%$ и (для сравнения) мелкозернистого песчаника (Дагестан; глубина залегания 5100 м) плотностью $\rho=2.18 \cdot 10^{3}$ кг $/ \mathrm{M}^{3}$ и пористостью $k=13 \%$.

Измерение теплопроводности в зависимости от гидростатического давления до 400 МПа в области температур 273-473 К в камере высокого давления проводилось абсолютным стационарным методом, описанном в [7]. Передающей давление средой служил газ аргон $\left(\lambda=0.019 \frac{B m}{\mathcal{M} \cdot K}\right)$.

Экспериментальные зависимости теплопроводности от давления и температуры приведены на рис. 1 и 2 соответственно. Для обоих образцов приведены зависимости теплопроводности гранулита от давления при $T=273 K, 373 K, 473 K$ (а) и при $P=0.1$ МПа, 100 МПа, 400 МПа .

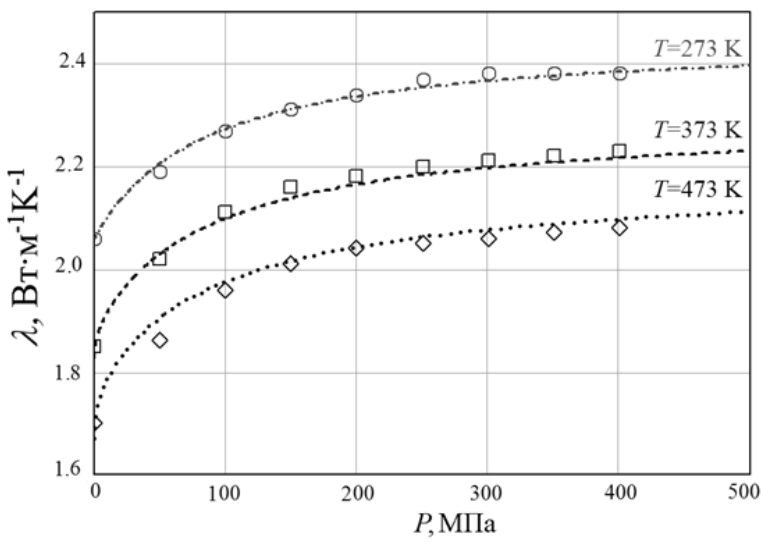

Рис. 1. а) Графики зависимости теплопроводности гранулита от давления

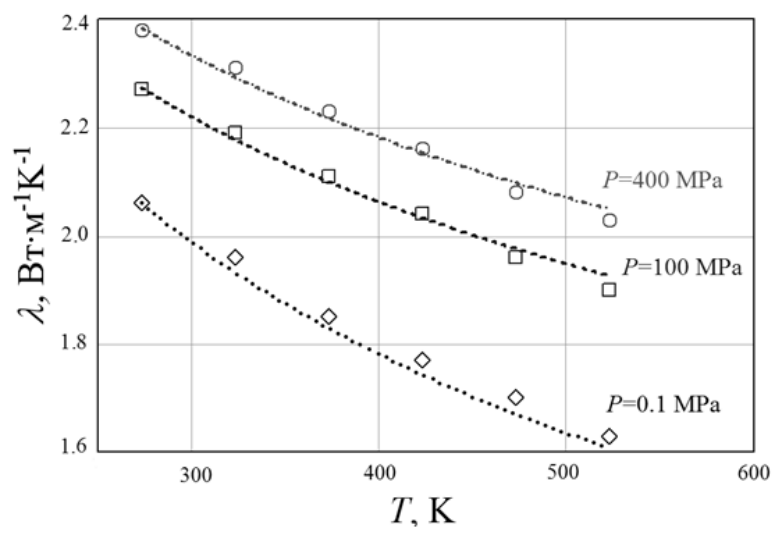

Рис. 2. а) Графики зависимости теплопроводности гранулита от температуры

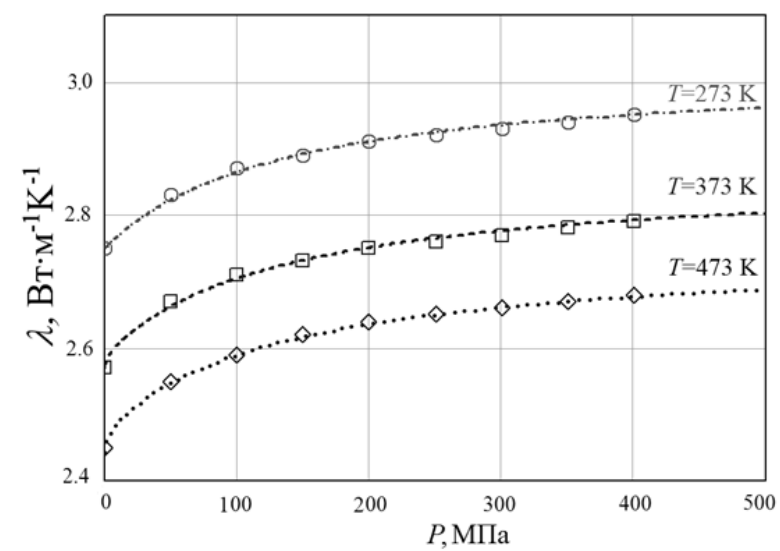

б) Графики зависимости теплопроводности песчаника от давления

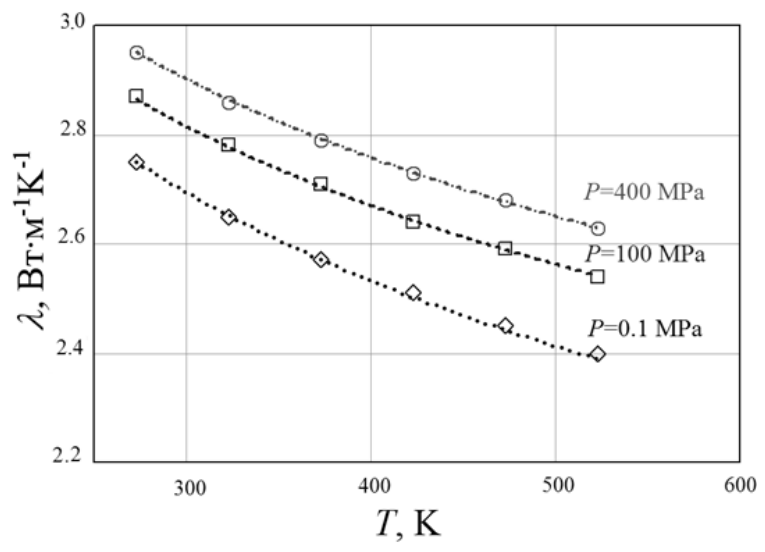

б) Графики зависимости теплопроводности песчаника от температуры

Как видим из рисунков, теплопроводность является функцией, зависящей от температуры и давления, т. е. $\quad \lambda(T, P)$, то есть 


$$
\lambda(T, P)=\lambda_{0} f\left(P_{n p .}\right) \cdot T_{n p .}^{n\left(P_{n p .}\right)}
$$

где $P_{n p .}=\frac{P}{P_{0}}, T_{n p .}=\frac{T}{T_{0}}, P_{0}=0.1 M \Pi a, T_{0}=273 K$. Здесь $f\left(P_{n p .}\right)$ и $n\left(P_{n p .}\right)-$ функции, зависящие от давления.

Функция $f\left(P_{n p}\right)$ имеет вид $f\left(P_{n p .}\right)=\frac{P_{n p .}+a}{b \cdot P_{n p .}+c}$, где $a, b, c-$ параметры, а функция $n\left(P_{n p .}\right)=d\left(1+P_{n p}\right)^{m}$, где $d, m-$ параметры. Значения параметров моделируются на основе экспериментальных данных. Для исследуемых образцов гранулитов значения параметров равны: $a=708.242, b=0.84, c=708.4, d=-0.41, m=-0.06$. Тогда уравнение (1) примет вид:

$$
\lambda(T, P)=\lambda_{0} \cdot \frac{P_{n p .}+708.242}{0.84 \cdot P_{n p .}+708.4} \cdot\left(T_{n p .}\right)^{-0.41 \cdot\left(1+P_{n p .}\right)^{-0.06}}
$$

где $\lambda_{0}=2.06$.

Для исследуемых образцов песчаника значения параметров равны: $a=1231.276$, $b=0.911, c=1231.365, d=-0.22, m=-0.026$. В результате уравнение (1) принимает вид:

$$
\lambda(T, P)=\lambda_{0} \cdot \frac{P_{n p .}+1231.276}{0.911 \cdot P_{n p .}+1231.365} \cdot\left(T_{n p .}\right)^{-0.22 \cdot\left(1+P_{n p} .\right)^{-0.026}}
$$

где $\lambda_{0}=2.75$.

Вместе с экспериментальными данными на рисунках 1 и 2 приведены графики зависимостей теплопроводности от давления и температуры, полученные по формулам (2) и (3) для гранулитов и песчаников соответственно. Как видно из рисунков, теоретические данные, полученные на основе уравнений (2) и (3), хорошо согласуются с экспериментальными данными.

\section{Заключение}

Полученные аналитические выражения для теплопроводности (2) позволяют определить теплопроводность саксонских гранулитов в зависимости от температуры и давления, что поможет моделированию процессов теплопереноса и прогнозированию глубинных температур, в том числе в призабойной зоне. Для сравнения проведён расчет температурно-барической зависимости для песчаников (3).

Работа выполнена при частичной поддержке РФФИ (гранты 20-08-00319 А и 1808-00059 A).

\section{Литература}

1. Alm O., Backstrom G. Thermal conductivity of KCL up to $19 \mathrm{kBar} / / \mathrm{High}$ Temperatures - High Pressures. - 1975. - V. 7. - P. 235.

2. Селезнев В.Е., Цыпкина Н.С., Петров А.В. и др. Влияние давления до 10 Кбар на теплопроводность $\mathrm{KCl}, \mathrm{Kl}, \mathrm{NaCl}, \mathrm{LiF} / /$ Физика твердого тела. - 1976. - Т. 18, вып. 5. C. 1423 . 
3. Higes D., Savin F. Thermal conductivity of dielectric solids at high pressure // Phys. Rev. - 1967. - V. 61, № 3. - P. 861.

4. Seipold U., Engler R. Investigation of the thermal conductivity of jointed granodiorites under uniaxial load and hydrostatic pressure // Gerlands Beiträge zur Geophysik. - Leipzig. 1981. - № 1. - P. 65.

5. Эмиров С.Н., Бейбалаев В.Д., Рамазанова А.Э. и др. О температурных и барических закономерностях изменения теплопроводности композитных материалов // Известия РАН. Сер.: Физика. - 2018. - Т. 82, № 7. - С. 142-145.

6. Emirov S.N., Beybalaev V.D., Amirova A.A. et al. Thermal conductivity temperaturepressure dependence of rocks and ceramics // Journal of Physics: Conf. Series. - 2019. V. 1172.

7. Abdulagatov I.M., Emirov S. N., Gairbekov Kh. A. Heat conductivity of porous glass at high pressures and temperatures. High temperature // Ind. Eng. Chem. Res. - 2002. - V. 41. P. 3586.

8. Воларович М.М., Баюк Е.И., Левикин А.И., Томишевская И.С. Физикомеханические свойства горных пород и минералов при высоких давлениях. - М.: Наука, 1974. $-223 \mathrm{c}$.

9. Пью Х.Л. Механические свойства материалов под высоким давлением. - М.: Мир, 1973. - 300 c.

10. Свенсон К. Физика высоких давлений. - М.: Изд-во ин. лит-ры, 1963. -218 с.

11. Лебедев Т.С., Корнин В.А., Савенко Б.Я. и др. Теплофизические свойства минерального вещества в термобарических условиях литосферы. - Киев: Наукова думка, 1988. - 248 c.

12. Kukkonen T., Jokinen J. and Seipold U. Temperature and pressure dependencies of thermal transport properties of rocks: implications for uncertainties in thermal lithosphere models and new laboratory measurements of high-grade rocks in the central fennoscandian shield // Surveys in Geophysics. - 1999. - T. 20. - P. 33.

Поступила в редакциию 18 марта 2020 2.

UDC 536.2

DOI: $10.21779 / 2542-0321-2020-35-3-31-35$

\section{Calculation of Thermal Conductivity of Granulites Depending on Pressure and Temperature}

\section{S.N. Emirov ${ }^{1}$, V.D. Beibalaev ${ }^{1,2,3}$, A.A. Aliverdiev ${ }^{1,2}$}

${ }^{1}$ Institute of Geothermy and renewable energy branch of the Institute; Russia, Republic of Dagestan, 367030, Makhachkala, Shamil aven., 43a; wemirov@mail.ru;

2 Dagestan State University; Russia, Republic of Dagestan, 367001, Makhachkala, M. Gadzhiev st., 43a; kaspij_03@mail.ru

${ }^{3}$ Dagestan State University of National Economy; Russia, Republic of Dagestan, 367008, Makhachkala, Ataev st., 5. 
The article deals with the problem of an empirical equation derived from experimental data on samples of Saxon granulites (Germany) for calculating the temperature-pressure dependences of thermal conductivity over a wide range of temperatures $(273-473 \mathrm{~K}$ ) and pressures (from atmospheric to 400 $\mathrm{MPa}$ ). The experimental measurements of thermal conductivity were carried out using the absolute stationary method. Argon gas served as a pressure transmitting medium. It is shown that the obtained equation successfully describes the experimental data, and by varying the equation parameters, temperature-pressure dependences can be described for a number of rocks. For a comparison, the temperature-pressure dependence for the Dagestan sandstones is calculated. The obtained analytical expressions would help to simulate heat transfer processes and predict deep temperatures, including in the hole-bottom region.

Keywords: thermal conductivity, pressure, temperature, granulites.

Received 18 March 2020 